\title{
LINHAS DO TEMPO: UM RESGATE HISTÓRICO DO INTERCÂMBIO ENTRE A UNEB E A UNIPD \& DO PROGETTO BEA COMO PERCURSOS QUE CONDUZIRAM A ORGANIZAÇÃO DO I COLÓQUIO BRASIL ITÁLIA
}

Nicola Andrian ${ }^{1}$

\section{Resumo}

O I Colóquio Brasil Itália é um evento científico de caráter internacional, promovido pelo PPGESA e realizado no DCH-III/UNEB, na cidade de Juazeiro-BA, nos dias 31 de julho (pré-colóquio) e de 21 a 23 de agosto, do ano de 2019. Quais foram as circunstâncias que determinaram a organização e a realização de um evento, até agora, único na sua espécie no referido contexto? Em um primeiro momento, este artigo tem como objetivo tornar públicas as linhas do tempo de dois caminhos percorridos por pessoas que acreditaram que o encontro e o diálogo entre sujeitos de diversas culturas podem fazer a diferença do ponto de vista humano e formativo. Caminhos que, cruzando-se, criaram as condições para a realização do evento. A análise dos dados coletados através de documentos, questionários e entrevistas apresenta a correlação entre diferentes experiências que, ao longo de décadas, criaram e fortaleceram relações entre pessoas e instituições brasileiras e italianas, através do desejo de superar distâncias (físicas, psicológicas, econômicas, culturais e sociais) e perpassar limites (polarizações e hierarquizações desumanizantes, prejuízos e racismo), para a formação de cidadãos capazes de viver e atuar no próprio contexto e pensar globalmente. Em um segundo momento o artigo apresenta as principais características do evento tais como o objetivo geral, as finalidades, o público alvo e a programação.

Palavras-chave: Educação contextualizada. Diálogo intercultural. Internacionalização acadêmica. Aprendizagem solidária. INTEREURISLAND.

\author{
LINEE DEL TEMPO: \\ UNA RICOSTRUZIONE STORICA DELLO SCAMBIO TRA LA UNEB E LA \\ UNIPD \& DEL PROGETTO BEA \\ COME PERCORSI CHE HANNO PORTATO ALL'ORGANIZZAZIONE DEL I \\ COLÓQUIO BRASIL ITÁLIA
}

\footnotetext{
${ }^{1}$ Bolsista do Programa Nacional Pós-doutorado PNPD, Coordenação de Aperfeiçoamento de Pessoal de Nível Superior (CAPES), vinculado ao Programa de Pós-graduação stricto sensu - Mestrado Multidisciplinar em Educação, Cultura e Territórios Semiáridos (PPGESA), Departamento de Ciências Humanas (DCH), Campus III da UNEB em Juazeiro-BA. Coordenador do Grupo permanente de internacionalização acadêmica DCH III / UNEB.
} 


\title{
Sintesi
}

Il I Colóquio Brasil Itália è un evento scientifico di carattere internazionale, promosso dal PPGESA e realizzato presso il DCH-III / UNEB, nella città di Juazeiro-BA, il 31 luglio (pre-colloquio) e dal 21 al 23 agosto, 2019. Quali sono state le circostanze che hanno determinato l'organizzazione e la realizzazione di un evento, finora, unico nel suo genere in questo contesto? In un primo momento, questo articolo si propone di rendere pubbliche le linee del tempo di due cammini percorsi da persone che hanno creduto che l'incontro e il dialogo tra soggetti di culture diverse possano fare la differenza dal punto di vista umano e formativo. Cammini che, incrociandosi, hanno creato le condizioni per la realizzazione dell'evento. L'analisi dei dati raccolti attraverso documenti, questionari e interviste mostra la correlazione tra le diverse esperienze che, nel corso di decenni, hanno creato e rafforzato relazioni tra persone e istituzioni brasiliane e italiane, attraverso il desiderio di colmare le distanze (fisiche, psicologiche, economiche, culturali e sociali) e oltrepassare i confini (polarizzazioni e gerarchie disumanizzanti, pregiudizi e razzismo) per la formazione di cittadini capaci di vivere e agire nel proprio contesto e pensare a livello globale. In un secondo momento l'articolo presenta le caratteristiche principali dell'evento quali l'obiettivo generale, le finalità, i destinatari e il programma.

Parole chiave: Educazione contestualizzata. Dialogo interculturale. Internazionalizzazione accademica. Service Learning. INTEREURISLAND.

\section{TIMELINES:}

\section{A HISTORICAL REVIEW OF THE EXCHANGE BETWEEN UNEB AND UNIPD \& OF THE PROGETTO BEA AS PATHS THAT LED TO THE ORGANIZATION OF THE I COLÓQUIO BRASIL ITÁLIA}

\begin{abstract}
The I Colóquio Brasil Itália is an international scientific event, promoted by PPGESA and held at the DCH-III / UNEB, in the city of Juazeiro-BA, on July 31 (pre-event) and from August 21 to 23, 2019. What have been the circumstances that have determined the organization and the realization of an event, until now, unique in this context? At first, this article aims to make public the timelines of two paths, crossed by people who believed that the encounter and dialogue between subjects from different cultures can make a difference from a human and educational point of view. Paths which, by crossing each other, created the conditions for the realization of the event. The analysis of the data collected through documents, questionnaires and interviews shows the correlation between the different experiences that, over decades, have created and strengthened relationships between Brazilian and Italian people and institutions, through the desire to bridge distances (physical, psychological, economic, cultural and social) and cross borders (dehumanizing polarizations and hierarchies, prejudices and racism) for the formation of citizens capable of living and acting in their own context and thinking on a global level. In a second moment the article presents the main characteristics of the event such as general objective, aims, target and program.
\end{abstract}

Keywords: Contextualized education. Intercultural dialogue. Academic internationalization. Service Learning. INTEREURISLAND 


\section{Introdução}

"Era uma vez ....", uma simples expressão que, ao começar uma história, parece ter a capacidade de superar as dimensões do cognitivo e do racional abrindo as portas às sensações e emoções no coração das leitoras e dos leitores e ouvintes. Uma forma tão apropriada a um conto de fadas quanto, poderia parecer, pouco pertinente a um artigo em uma revista científica.

Mais o I Colóquio Brasil Itália foi pensado, planejando e realizado com a consciência de quanto oportuno, talvez necessário, pudesse ser o quebrar alguns paradigmas e algumas barreiras, de quanto pertinente pudesse ser o superar alguns limites, perpassando fronteiras entre culturas, entre o mundo acadêmico e a comunidade, entre a teoria e a prática, entre o racional e o emocional ... entre o Local e o Global.

Mais, no final da história, quais foram as circunstâncias que determinaram a organização do I Colóquio? A resposta a questão norteadora desse artigo vem do resgate histórico de dois caminhos percorridos por pessoas que acreditaram que o encontro e o diálogo entre sujeitos de diversas culturas podem fazer a diferença do ponto de vista humano e formativo. Experiências que, ao longo de décadas, criaram e fortaleceram relações entre pessoas e instituições brasileiras e italianas, através do desejo de superar distâncias (físicas, psicológicas, econômicas, culturais e sociais) e perpassar limites (polarizações e hierarquizações desumanizantes, prejuízos e racismo), para serem cidadãos capazes de viver e atuar no próprio contexto e pensar globalmente. ${ }^{2}$

\section{Os caminhos percorridos}

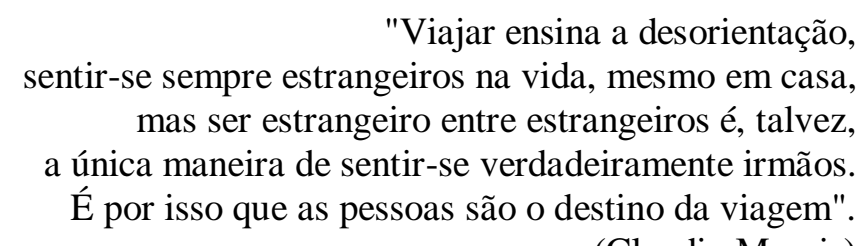

(Claudio Magris)

Entre os dois cominhos que serão narrados a seguir, o mais longevo começou no ano de 1995 através das primeiras atividades realizadas pelo Gianni Boscolo ${ }^{3}$, na época professor de Filosofia da Ex Faculdade de Educação da Bahia-FAEEBA (de agora em diante Ex FAEEBA), atual Departamento de Educação-DEDC do Campus I da UNEB em Salvador BA, que pode ser considerado, a pleno título, o precursor do intercâmbio.

\footnotetext{
${ }^{2}$ Desde já pedimos a compreensão de leitoras e leitores se não for possível, por questões de espaço e tempo, mencionar neste artigo todas/os as/os protagonistas dessas experiências. Tomamos essa condição como um belo desafio para escrever mais em um próximo futuro.

${ }^{3}$ De nacionalidade italiana, nascido em 'Costa di Rovigo', na província de Rovigo, na Região do Veneto, na Itália, depois de concluir a especialização em Didática no Ensino Superior na Universidade Católica de Salvador-BA, no Brasil, conseguiu o título de Mestre e Doutor em Educação pela Universidade Federal da Bahia - UFBA.
} 
Desde quando veio ao Brasil, como sacerdote da Igreja Católica (em 1973), o Prof. Gianni B. manteve o sonho de criar as condições de encontro e diálogo entre as culturas brasileira e italiana em todos os lugares aonde teve a possibilidade de desenvolver atividades educativas. "Eu sempre pensava em como ajudar as pessoas a crescer tendo contato com pessoas de culturas diferentes, mas não porque essas fossem superiores, mas sim, diferentes" (BOSCOLO, G., 2020)

Com o apoio da Direção e o interesse de alguns professores e estudantes em desenvolver contatos com pessoas de outros países, no ano de 1996 realizou-se o primeiro curso de língua italiana da UNEB, promovido pela Ex FAEEBA. Reconhecido como uma atividade de extensão, divulgado nas salas de aula e oferecido de forma gratuita, tal curso proporcionou uma abertura à cultura italiana através do idioma e da música, que muitas vezes facilitava o aprendizado da língua ${ }^{4}$. Em um clima de novidade e grande curiosidade, o curso foi o ponta pé inicial para as primeiras experiências de mobilidade de professores e estudantes da mesma faculdade com destino à Itália ${ }^{5}$. Em janeiro do ano de 1996, um grupo de seis professores realizou a chamada 'viagem de exploração', com o intuito de conhecer o contexto nativo do professor e criar os vínculos e as condições para desenvolver, de fato, atividades de intercâmbio. Uma etapa importantíssima desta viajem foi a visita à Universidade de Padova, principalmente à Ex Faculdade de Ciências da Formação (de agora em diante Ex ScForm/UNIPD), que proporcionou o encontro com diversas pessoas, entre professores e técnicos, que foram determinantes para a realização de algo que até aquele momento ainda era somente um sonho ${ }^{6}$.

Ouvindo e lendo as histórias contadas pelas pessoas entrevistadas, é emocionante o imaginar como pode ter sido desafiador e estimulante o preparo da primeira viagem de estudantes e quantas semelhanças esse caminho tem com o segundo que será relatado a seguir, principalmente a respeito de sensações, emoções, motivações, desafios experimentados e vivenciados pelas pessoas envolvidas e que determinaram o sucesso de algo tão novo e diferente. Segundo o depoimento do Prof. Gianni B., muitos foram os detalhes considerados ao pensar na possibilidade da mobilidade estudantil à Itália, como por exemplo: Quem viajaria? Qual o preparo para tal experiência? Quem garantiria do ponto de vista econômico as passagens aéreas e a hospedagem na Itália? A onde as/os estudantes seriam alojados e quais atividades teriam realizado ao longo do tempo da estadia? Quanto tempo de estadia na Itália? De que forma seriam reconhecidas formalmente as atividades realizadas pelas estudantes ao voltar na própria faculdade? Etc etc. Além das questões acima mencionadas, pode-se pensar como poderia ter sido o preparo ao possível choque climático, saindo do verão do Nordeste brasileiro para

\footnotetext{
${ }^{4}$ Acha-se relevante o fato que o Prof. Gianni B. chegou a levar na sede da Ex Faculdade o próprio piano, para poder trabalhar a língua e a cultura italianas através da música. Algo que diz a respeito do compromisso com as atividades propostas e desenvolvidas (dados da entrevista).

5 Interessante o fato que desde o ano de 1999 a telenovela 'Terra Nostra', produzida pela Rede Globo, despertou um grandíssimo interesse para a Itália e a sua cultura.

${ }^{6}$ Entre as/os demais citadas/os nas entrevistas e nos questionários: a Profa. Fabrizia Antinori, na época Diretora da Ex ScForm/UNIPD, a Profa. Patrizia Zamperlin, representante da mesma faculdade na comissão para o exterior da UNIPD, o Prof. Giuseppe Milan, na época Prof. de Pedagogia Especial, posteriormente delegado pelo departamento FISPPA para as relações entre a UNIPD e as universidades da América Latina, e a Dra. Tiziana Pampanin, técnica administrativa.
} 
mergulhar no inverno italiano que, nas cidades de Rovigo e Padova, chega a proporcionar épocas de frio com temperaturas abaixo de zero e até com neve.

A primeira experiência de mobilidade estudantil foi diferente de todas as demais antes de tudo pelo fato de ter acontecido ainda sem um acordo formal assinado entre as duas Ex Faculdades ou Universidades. Ao longo do ano de 1996, foram selecionadas quatro estudantes que tinham participado ativamente ao curso de língua e cultura italiana e que passaram por uma prova final e por uma entrevista, tendo apresentado documentos pessoais e acadêmicos tais como o comprovante de matrícula e o histórico escolar. Determinou-se, para esta primeira experiência, um período de três meses e meio, entre o dia 22 de janeiro e o dia 21 de abril de 1997 e como primeiro destino a cidade de Rovigo. As despesas foram custeadas pela Reitoria da UNEB, na figura da Reitora Ivete Sacramento e posteriormente do Reitor Lourisvaldo Valentim da Silva, que sempre incentivaram o intercâmbio, com o apoio, também, de alguns amigos da Itália.

Segundo as protagonistas destas primeiras experiências de intercâmbio, tudo era novo e muito desafiador. Por muitas delas, além de ser a primeira viagem internacional, foi a primeira vez de avião. Para Cínthia Maria Seibert Santos, na época estudante do curso de graduação em Pedagogia da FAEEBA, as motivações principais que a levaram a fazer parte do primeiro grupo, em 1997, foram:

\begin{abstract}
A ampliação de possibilidades acadêmicas, o conhecimento de uma outra cultura, o desejo de aperfeiçoar o idioma, conhecer a realidade das escolas italianas, suas práticas, currículos, processos de alfabetização, intercâmbio com a Universidade e interação com as atividades do Núcleo de Informática Educacional da Faculdade de Magistério da Universidade de Padova'. (SEIBERT SANTOS, C.M., 2020)
\end{abstract}

Mesmo com um tempo relativamente breve de estadia na Itália, as quatros estudantes que abriram o caminho do intercâmbio, vivenciaram diversas e ricas experiencias em várias instituições e contextos do chamado 'Bel Paese'. Segundo os depoimentos do Prof. Gianni B. (2020) e de Cíntia Maria S.S. (2020), elas tiveram a oportunidade de visitar e conhecer algumas escolas maternais nas cidades de Rovigo (aonde elas residiram para a primeira temporada da viagem), Badia Polesine e Fiesole, podendo participar de atividades em alguns espaços de educação formal e não formal tais quais a Casa della Divina Provvidenza - Istituto per Fanciuli Sinti (em Badia Polesine), o Centro de orientação e inciativas para a América Latina Bambini di Strada (em Florença), a instituição La Nostra famiglia (em Udine).

Participamos também de iniciativas junto ao Projeto Ágata Esmeralda, em Firenze, na Paróquia de Badia Polesine, dando depoimentos e relatos de experiências sobre a educação no Brasil e no Collegio Don Mazza, onde estivemos hospedadas durante o período que frequentamos a Universidade em Padova com a realização de um evento junto ao Centro di Aiuto Alla Vita (Dal Brasile un progetto di vita: Agata Esmeralda a Salvador Bahia). (IBIDEM, 2020)

A respeito das interações especificamente acadêmicas, a maior participação das quatros estudantes baianas se deu na Universidade de Padova, chegando a cursar 
disciplinas tais quais 'Computação geral e tecnologias educacionais', 'Tecnologias Educacionais' e 'Metodologia da Pesquisa Educacional'. Além disso, outras experiências foram vividas na Ex Faculdade de Educação da Universidade de Florença, na Universidade de Roma - Foro Itálico e na Universidade de Língua Italiana para estrangeiros na cidade de Siena.

Tentando imaginar a riqueza de tantas vivências, é com as palavras das protagonistas que se ressalta a importância das relações interpessoais autênticas que geram e permitem um diálogo intercultural real, concreto a partir do fato que qualquer instituição, seja ela pública ou privada, ou qualquer grupo, seja ele formal o informal, são constituídos por pessoas. E são essas mesmas pessoas que, autoras e produtoras de conhecimentos, competências, hábitos, valores, crenças, isto é, de culturas, determinam o valor de cada encontro e as consequências deles.

\begin{abstract}
Além de termos conhecido cidades italianas, história, cultura, fortalecimento de vínculos com pessoas e instituições, conhecer como as pessoas vivem, o dia a dia de famílias, pois, enquanto estivemos em Padova e Rovigo ficamos em casas de amigos do professor Gianni Boscolo, além de termos sido hospedadas em Firenze em um Convento. Essa amplitude de possibilidades contribui muito com a experiência do intercâmbio, extrapolando a dimensão acadêmica, mas trazendo conteúdos de vida e para a vida. (IBIDEM, 2020)
\end{abstract}

Uma das principais consequências concretas nesta primeira viagem foi a assinatura do primeiro acordo de cooperação pelas Direções da Ex FAEEBA, Campus I, UNEB e da Ex ScForm/UNIPD, em data 25 de fevereiro de $1997^{7}$ e tendo validade de três anos. Tal documento institucionalizou a proposta inicial e as demais experiências de mobilidade que se realizaram cada vez mais no marco de um vínculo entre pessoas e instituições.

"Fazer parte de um intercâmbio muda completamente a nossa percepção das coisas. Para participar é importante ter uma boa base formativa, ter clareza do que vai fazer e força." é o que nos diz Edilane Carvalho Teles (TELES, E.C., 2020), na época estudante de pedagogia da Ex FAEEBA e atual professora do DCH III da UNEB, que fez parte da terceira turma de mobilidade estudantil, entre o mês de outubro de 1998 e março de 1999. Ela, também, nos traz a reflexão sobre o valor e o significado de uma experiência de intercâmbio no processo formativo de estudantes universitários, tanto do ponto de vista profissional como humano. Ao ser selecionada, Edilane C.T. apresentou um trabalho na forma de Tese monográfica, cujo título foi 'Brasil Viva', relatando sobre alguns aspectos da educação no Brasil e trazendo a reflexão sobre a problemática das crianças carentes, no especifico as crianças de rua. Como última etapa antes da viagem, a estudante concordou com a própria orientadora (uma docente da Ex FAEEBA nomeada para acompanhar a experiência) os objetivos e um plano de atividades a serem desenvolvidas, incluindo as disciplinas que escolheu cursar entre as demais propostas pela Ex ScForm/UNIPD.

\footnotetext{
${ }^{7}$ Nas pessoas da Ex Diretora Profa. Ivanê Dantas Coimbra, pela Ex FAEEBA/UNEB e da Ex Diretora Profa. Mirella Chiaranda, pela ScForm/UNIPD.
} 
Eu escolhi cursar duas disciplinas, tais quais Pedagogia Especial com o prof. Giuseppe Milan e Tecnologias da educação com a Profa. Bianca Maria Varisco. Esse último foi o que mais me marcou porque o meu interesse era desenvolver um estudo sobre tecnologias e mídia e porque no Departamento de Educação Campus I, UNEB não tinha nem uma disciplina relacionada as tecnologias da educação. Foi uma experiência muito boa e a primeira oportunidade de estudar aquilo que se tornou a minha área de interesse profissional e tais estudos me seguem até hoje. Até no memorial do Doutorado eu cito o intercâmbio e cito a influência da professora. Foi algo que me marcou tanto do ponto de vista acadêmico como da vida pessoal. (IBIEM, 2020)

Nesse processo formativo tem uma grande relevância a abordagem do ponto de vista de experiências que possam facilitar a conscientização, a desconstrução e a superação de fronteiras, que podem ser reconhecidas como situações limites (de acordo com a fala de Paulo Freire na obra, Pedagogia do Oprimido), como, por exemplo, preconceitos e diferentes formas de racismo.

O intercâmbio se desenvolveu entre muitas expectativas e muitos desafios, entre muito estudo e atividades diversas, mais o meu objetivo principal sempre foi o estudo. Vivenciamos muitas diferenças culturais, de hábitos e na época em que eu fui achei o país da Itália muito preconceituoso, patriarcal e moralista [...], isso me chocava e me incomodava. [...], mas eu aproveitei a cada momento desta experiência e agradeço a quem faz parte desse projeto, primeiramente ao Prof. Gianni B., que possibilitou isso. (IBIDEM, 2020)

Ao longo desse primeiro ciclo foi possível dar início a um verdadeiro intercâmbio abrindo o caminho, também, para estudantes da Ex ScForm/UNIPD, versus a FAEEBA, em Salvador. E nesse novo horizonte, mais uma fronteira ia ser perpassada através dessas experiências. A fronteira entre a universidade e a própria comunidade através de práticas e processos de extensão. Naquele tempo o Prof. Gianni B. era secretário executivo da Ong Agata Esmeralda Onlus que tinha vínculo com 175 escolas em vários municípios da Bahia: "Montamos uma equipe com educadores e assistentes sociais que tivessem a responsabilidade de atividades realizadas em várias escolas e as estudantes italianas vindo para o Brasil, participaram do intercâmbio com atividades nas escolas que tinham vínculos com a Agata Esmeralda." (BOSCOLO, G. 2020). As/os intercambistas da Itália, ao chegar em Salvador, visitavam algumas dessas escolas e escolhiam em qual delas realizar a própria experiência prática, que, ao voltar à Itália, ia ser reconhecida como estágio ou tirocínio curricular pela própria Ex ScForm/UNIPD.

$\mathrm{Na}$ elaboração dos dados coletados, principalmente no estudo dos documentos oficiais redigidos e assinados pelas duas ex faculdades e universidades, muito interessante foi o fato que houve um caminho percorrido, também, através das relações formais entre as duas instituições. Após os primeiros três anos, o segundo acordo foi assinado entre a UNEB como um todo (não mais somente FAEEBA, Campus I) e, ainda, a Ex ScForm/UNIPD, no dia 6 de dezembro de 2002 e tendo validade de mais três anos. Os seguintes Acordos, chamados de Memorandum of Undestanding (MoU) foram assinados 
entre as duas Universidades $^{8}$, mantendo a validade de 3 anos cada um, renováveis. Considera-se esse como um dado significativo que relata a importância do intercâmbio tanto pela UNEB como pela UNIPD.

Refletindo e as vezes se deixando levar pelas informações recolhidas através de entrevistas, questionários e documentos percebeu-se logo a riqueza de atividades e propostas que o intercâmbio proporcionou tanto no Brasil Como na Itália, algumas das quais foram bem além do que podia-se pensar ou esperar no começo deste caminho. Para o Prof. Gianni B.(IBIDEM, 2020), foram muito significativos por exemplo: um curso de graduação para 100 professores das escolas comunitárias de Salvador, com a presença de um professor convidado da Universidade de Padova (96 desses alunos conseguiram o diploma de Ensino Superior pela UNEB); um curso de especialização em Farmácia para 20 farmacêuticos de Salvador e convidados ${ }^{9}$; um curso de especialização para Juizes, Advogados, e Delegados do Estado da Bahia que teve uma primeira fase na Bahia e uma segunda fase na Universidade de Padova. ${ }^{10}$ Como relatado pela Profa. Patrizia Zamperlin (ZAMPERLIN, 2020), em Padova, a mobilidade estudantil versus a Bahia abriu-se também para alunas/os dos Master (especializações) da UNIPD. Em 2002, a experiência de dois estudantes matriculados no Master em Estudos interculturais levou a cabo a edição e publicação do Livro 'Ad occhi aperti' (TURUS, G., 2002). Outras experiências de grande impacto e pioneiras a respeito de fronteiras perpassadas entre a universidade e a comunidade foram os núcleos de estudos de italiano, criados tanto em Salvador-BA, tais quais o Núcleo de Estudos de Italiano - NESTI, como órgão da UNEB e a Associação Sócio Cultural PATÍ ${ }^{11}$, como em Padova, o Grupo GritaBrasil ${ }^{12}$.

A primeira década de colaboração, internacionalização e diálogo intercultural foi comemorada com a realização do Seminário "Educação e Interculturalidade Aproximando Culturas. A experiência de troca entre o Brasil e a Itália", no Campus I em Salvador-BA, nos dias 11 e 12 de dezembro de 2006. Um evento realizado pela Pro Reitoria de Extensão PROEX, pelo Departamento de Educação Campus I e pelo NESTI/UNEB em colaboração com a Associação Científica e Sócio Cultural PATI ${ }^{13}$,

\footnotetext{
8 Acordos assinados nas datas: 14/02/2005 (3 anos); 29/01/2008 (3+ 3 anos); 21/05/2015 (3 anos) e 24/09/2018 (3 anos).

${ }^{9}$ Ministrado pelo Prof. Antonio Bettero da Ex Faculdade de Farmácia da Universidade de Padova.

${ }^{10}$ Curso este coordenado pela UNEB/PATÍe pelo Ministério Público Estadual na pessoa do dr. Gedder Rocha. Entre as demais

${ }^{11}$ Esta Associação configura-se como uma Organização Não Governamental (ONG), sem fins lucrativos, e que vem se propondo a: Desenvolver o espírito de cooperação, favorecendo intercâmbios institucionais; Oferecer, às entidades comunitárias, apoio técnico para obtenção de recursos nacionais e internacionais; Fomentar atividades educacionais com professores, gestores, alunos e demais sujeitos envolvidos nas escolas comunitárias e em outras instituições públicas e privadas; e oferecer suporte técnico-pedagógico para cursos de língua e cultura italianas. Material disponível no site: http://www.pati.org.br

${ }^{12} \mathrm{O}$ grupo GritaBrasil é parte integrante da Comunidade de pesquisa e práticas Educação Sem FronteirasEsF, nasceu com a vontade de aumentar a riqueza de experiências vividas em primeira mão por estagiários e pesquisadores italianos no Brasil ou estudantes brasileiros na Itália, em uma lógica de intercâmbio e compartilhamento mútuo através de: um curso básico de língua portuguesa; reuniões temáticas, discussões e depoimentos; compartilhamento de experiências de estágio e pesquisa realizadas no Brasil; comparação intercultural entre estudantes italianos e brasileiros.

Os encontros eram gratuitos e abertos não apenas aos estudantes, mas a todos os interessados.

${ }^{13}$ Comissão organizadora Ana Paula Borges, Cínthia Seibert e Teresa Cristina Fernandes. Coordenação Profa. Dr.a Alda Muniz Pepe e Prof. Dr. Gianni Boscolo. Material disponível no site: http://www.pati.org.br/index.html
} 
tendo como público alvo professores e alunos de graduação e pós-graduação em pedagogia e áreas afins. Nas linhas do tempo relatadas nesse artigo, o seminário acima citado tem um grande valor, colocando-se como o primeiro ponto de encontro dos dois caminhos apresentados. ${ }^{14}$

$\mathrm{O}$ acordo atualmente em vigência entre as duas universidades é um dos quatro (4) acordos de cooperação que a UNEB atualmente tem com universidades conveniadas italianas e um dos dez (10) acordos bilaterais para a mobilidade de estudantes que não fazem parte do programa ERASMUS e que a UNIPD tem com universidades brasileiras. Tal acordo consta de um Termo de Cooperação e de um Protocolo Adicional, ambos assinados pelos próprios Reitores no dia 24 de setembro de 2018, com vigência de três anos e com a possibilidade de mobilidade de estudantes, de até seis meses e de qualquer departamento de ambas as universidades, de pesquisadores e de professores.

Por uma série de razões, a partir do ano de 2012 as atividades de intercâmbio pararam de ambos os lados, abrindo uma época de inatividade que poderia ter levado à não prorrogação do acordo entre a UNEB e a UNIPD, se não tivesse acontecido o cruzamento e o encontro com o segundo dos dois caminhos aqui apresentados.

\subsection{O Progetto BEA e os vínculos entre a Associação EnARS, a UNIPD, a Ex FFPP/UPE a PROEX/UNIVASF}

“A DECENTRALIZAÇÃO: Estar na situação de 'estrangeira' me fez pensar muito na capacidade de sair do meu mundo, da minha maneira de pensar, na capacidade de me 'afastar de mim.. ${ }^{15}$

O segundo caminho percorrido nasce e se desenvolve na cidade de Petrolina, no Estado de Pernambuco, situada no lado oposto do Rio São Francisco respeito à cidade de Juazeiro-BA e é a história do projeto social e de intercâmbio Progetto $B E A^{16}$, promovido pela associação EnARS ${ }^{17}$ de Padova e pelo BEA Centro de estudos e práticas, de Petrolina, que tem como objetivo geral:

Desenvolver boas práticas interculturais, educacionais e de formação, por meio de experiências mistas de estudo e estágio universitário e de voluntariado no exterior, em relação com crianças, adolescentes e mulheres em condições de risco e vulnerabilidade social. Especial atenção é dada aos momentos de encontro e intercâmbio intercultural de estudantes e voluntários universitários, para a promoção da cidadania ativa e da responsabilidade social no mundo. (EnARS, 2020, tradução do autor)

\footnotetext{
${ }^{14} \mathrm{Na}$ apresentação do próximo caminho será relatado de forma completa esse momento de interação.

${ }^{15}$ Relatório Final - Giulia Pivato, Equipe BEA 2015, Curso de Graduação em Ciências da Educação e da Formação, SED, FISPPA, UNIPD Padova, Itália.

${ }_{16}$ Material e informações disponíveis no site: http://www.enars.it/joomla/en/progetti/progetto-bea

${ }^{17}$ Associação EnARS, Enzima Ativa para Redes Sociais, está presente no território de Pádua e sua província desde 1977, sempre interessada em políticas comunitárias, com especial atenção às políticas de juventude e a promoção da cidadania ativa por meio de processos participativos. Informações no site: $\underline{\text { www.enars.it }}$
} 
O primeiro passo dessa caminhada se deu no ano de 2000, com a experiência de estágio no exterior de Nicola Andrian ${ }^{18}$, na época estudante do curso de graduação em Ciências da Educação da Ex ScForm/UNIPD. A mesma Faculdade que no ano de 1997 tinha assinado o primeiro acordo com a Ex FAAEBA. A experiência de estágio foi tão marcante que determinou a volta em Petrolina do estudante, nos meses de Julho e Agosto do ano de 2001, com o desejo de fortalecer os vínculos com as pessoas e as instituições conhecidas e mergulhar mais profundamente na cultura do nordeste brasileiro, aprimorando o conhecimento teórico/prático da realidade dos 'meninos de rua' e de crianças e adolescentes em situação de vulnerabilidade social. Procurar notícias e informações a respeito de propostas formativas para educadores (tanto no contexto escolar como em contextos extra escolares), que atuassem com esses perfis na cidade de Petrolina, foi uma das atividades mais intensas realizadas nessa segunda temporada de mobilidade internacional. Acreditando que 'Nada é por acaso' pode-se reconhecer o valor de um encontro com um professor universitário de Petrolina ${ }^{19}$ que, um belo dia ao longo do mês de julho de 2011, procurou pelo telefone o citado estudante com o intuito de conversar um pouco em inglês, imaginando que um italiano tivesse um bom domínio desse idioma. Ao encontrar-se e conhecer-se, tal professor levou pela primeira vez o estudante a conhecer a própria universidade, enquanto, com certeza, nem um dos dois podiam imaginar o que aquela simples visita teria determinado ao longo de décadas. Aquele final da tarde na Ex Faculdade de Formação de Professores de Petrolina-FFPP da Universidade de Pernambuco-UPE (de agora em diante Ex FFPP/UPE) foi iluminante e viabilizou a proposta de um trabalho coletivo de planejamento e implementação de um projeto de cooperação internacional e de pesquisa que pudesse ser considerado, também, como trabalho de conclusão do curso de graduação. O encontro e o diálogo com alguns professores da Ex FFPP/UPE, determinaram os primeiros passos de algo que até aquele momento era somente um sonho. Segundo a fala do Prof. Ivanildo Alves de Almeida:

O nosso primeiro encontro se deu em 2001, na UPE Campus Petrolina. O prof. Francisco de Assis Silva, de Letras, me apresentou a Nicola Andrian na porta da sala de aula do I Período de Pedagogia, no qual eu trabalhava Metodologia Científica (I Pedag.). Lembro-me bem: estávamos os três em frente um mural/pintura em homenagem a Paulo Freire, fixado na parede externa da sala. Conversamos rapidamente e combinamos de conversar mais demoradamente: Nicola sugeriu participar das minhas aulas numa turma, eu lhe informei que trabalhava também em Pedagogia com Antropologia Cultural (III Pedag.) e Pesquisa em Educação (IV Pedag.). (ALVES DE ALMEIDA, I., 2020)

\footnotetext{
${ }^{18}$ Autor do presente artigo, realizou a experiência de mobilidade internacional, nos meses de Julho e Agosto do ano de 2000, como estagiário da UNIPD e como voluntário da Ong VIDES (Voluntariado, Mulher, Educação e Desenvolvimento) de Roma, na Associação dos Amigos do PETRAPE, fundada pela Freira Irmã Maria Euridice Dourado (da congregação das Filhas de Maria Auxiliadora) que cuidava e ainda cuida de crianças e adolescentes de e na rua e em condição de vulnerabilidade social.

${ }^{19}$ Francisco de Assis Silva Panta, Professor Assistente do Curso de Licenciatura em Letras Português e Inglês e suas literaturas da Ex Faculdade de Formação de Professores de Petrolina-FFPP da Universidade de Pernambuco-UPE.
} 
Os encontros se intensificaram e nessa temporada conseguiu-se coletar dados tanto na Ex FFPP/UPE como no PETRAPE e em outras instituições que abordavam a acolhida e o cuidado de crianças e adolescentes em condição de risco e vulnerabilidade social, tais quais a Escola Municipal São Domingos Savio ${ }^{20}$, o Centro Maria Auxiliadora Pro Menor Carente/CEMAM e a Ex Fundação da Criança e do AdolescenteCenip/FUNDAC (atual FUNASE), de Petrolina. O interesse era construir juntos um percurso de formação tanto de professores como de profissionais e voluntários que trabalhavam com esse perfil, considerando o fato que, naquela época, a cidade não oferecia nada nesse nível. Tal riqueza de material permitiu a redação de uma proposta de projeto de cooperação internacional cujo título foi BEA 2002, que teria sido apresentada, através da Associação EnARS, em um edital de Cooperação para o desenvolvimento e solidariedade internacional (em italiano: Cooperazione Decentrata) da Região do Veneto, Itália.

A aprovação e o cofinanciamento da proposta foi um grandíssimo impulso para o começo de uma série de atividades que se desenvolveram graças a uma rede de colaborações entre universidades, instituições públicas e privadas dos contextos de Petrolina-PE, no Brasil, Padova e Rovigo na Itália ${ }^{21}$.

Entre o mês de agosto de 2002 e o mês de dezembro de 2004, desenvolveu-se um projeto em três etapas com a realização de um Curso de formação específica para professores da Escola São Domingo Sávio e operadores do PETRAPE com a participação de nove professoras/es e cerca de 300 estudantes da Ex FFPP/UPE.

Eu digo que foi uma experiência extraordinária e inesquecível, considerando a riqueza de situações pedagógicas, encontros profissionais e acadêmicos riquíssimos culturalmente. $\mathrm{O}$ aspecto de proporcionar aos estudantes experiências vivenciais na Escola São Domingos Sávio (no PETRAPE) foi muito marcante e trouxe uma perspectiva do distanciamento entre a Universidade e a educação básica, naquela situação de risco e vulnerabilidade social, até então praticamente nova pois que o ECA, recém aprovado e já em vigor, obrigou a universidade a repensar sua atuação na comunidade e passou a buscar inserções nesses espaços formativos para melhor compreendêlos e poder colaborar pedagogicamente. (IBIDEM, 2020)

Essa primeira experiência de diálogo e cooperação internacional, mesmo tendo apresentando ao longo dos três anos vários pontos críticos, foi altamente significativa e com repercussões que abriram novas possibilidades de colaboração. Entre as demais, no final do ano de 2004 (de 1 a 4 de dezembro), uma delegação da Ex FFPP/UPE foi convidada a participar do evento científico $V$ Biennale sulla didattica universitaria ${ }^{22}$ da

\footnotetext{
${ }^{20}$ Escola Municipal São Domingos Sávio, sediada na Rua Barão da Boa Vista, no Gercino Coelho em Petrolina, que foi fundada pela Irmã Maria Eurides Dourado e na qual estudavam a maioria das crianças e dos adolescentes acolhidos, na época, pelo PETRAPE.

${ }^{21}$ Ex FFPP/UPE, Associação dos Amigos do PETRAPE, Associação de Pais e Amigos dos ExcepcionaisAPAE Petrolina, Ex FUNDAC (Atual FUNASE) Petrolina, Prefeitura de Petrolina, no Brasil, UNIPD, EnARS e Região do Veneto, na Itália.

${ }^{22}$ V Bienal da Didática Universitária (tradução do autor) com a participação da Ex Diretora Prof.a Maria do Socorro Ribeiro Nunes, da Ex Vice Diretora Profa. Dires Guerra de Morais Torres e do Prof. Ivanildo Alves de Almeida, apresentando reflexões que constam nos Anais do evento, publicados em 2006.
} 
Ex ScForm/UNIPD em Padova. Começaram a brotar, assim, colaborações institucionais que, no ano de 2005, levaram a Ex FFPP/UPE e a Ex ScForm UNIPD a assinar um acordo de colaboração que previa, entre outras atividades, o intercâmbio de estudantes e professores, com validade de três anos e que foi prorrogado por mais um ciclo até o 2010²3; no mesmo ano a EnARS a assinar um acordo de formação e orientação com a Universidade de Pádua, para receber e orientar estudantes interessados em experiências de estágio formativo no exterior. Para a Isabella Polloni, Presidenta do EnARS e o coordenador do projeto:

[...] o encontro entre pessoas, o diálogo e a colaboração 'em pé de igualdade' constituem o Coração de uma abordagem intercultural e de um relacionamento autêntico. Eles são uma fonte de grande riqueza para o bem-estar dos seres humanos e das sociedades e para uma melhor gestão e resolução das situações de necessidade que cada comunidade está enfrentando. (ANDRIAN, N.; POLLONI, I., 2020, tradução do autor)

Sempre no ano de 2005, a nova trilha desenhada pelo Progetto BEA cruzou o próprio caminho com as trilhas do Grupo GritaBrasil, vinculado ao intercâmbio UNEB UNIPD, com a Comunidade de pesquisa e práticas Educação Sem Fronteiras-EsF e o programa de estágios formativos no exterior vinculados à Ex ScForm/UNIPD. Através desses novos vínculos formais, abriu-se o grande horizonte da mobilidade de estudantes para experiências de estágio formativo que foi se aperfeiçoando com um novo ciclo entre os anos de 2005 e 2008. A primeira dupla de estudantes da Ex ScForm/UNIPD, desenvolveu o próprio estágio no mesmo ano de 2005 e desde então até o ano de 2019, ano de realização do I Colóquio Brasil Itália, foram 47 as/os estudantes da UNIPD que vivenciaram experiências de aprendizagem solidária internacional (Service Learning Internazionale) através do Progetto BEA.

Para Roberta Gallo, uma das primeiras, a experiência de mobilidade internacional realizou-se para desenvolver o estágio obrigatório de 250 horas do curso de graduação em Educador social, cultural e territorial da Ex ScForm/UNIPD. Foram três meses de atividades na Associação dos Amigos do PETRAPE, com crianças e adolescentes em situação de vulnerabilidade social. "Eu acho que foi a primeira experiência forte que me permitiu abrir mente e coração, começar a amar um país maravilhosamente vivo, contraditório e colorido que carrego em meu coração desde então e que felizmente pude conhecer melhor graças a outras 3 viagens." 24 . Ao desenvolver as atividades planejadas, a estagiária resolveu escrever o Trabalho de Conclusão de Curso sobre a experiência, cujo título foi 'A relação educativa com menores brasileiros em situação de risco'.

Minha tese foi elaborada a respeito dos processos de criação e de desenvolvimento das relações educativas que eu consegui aprimorar

\footnotetext{
${ }^{23}$ Nas pessoas do Ex Diretor Prof. Luciano Galliani, pela Ex ScForm/UNIPD e da Ex Diretora Profa. Rosilande Ribeiro Bandeira, pela Ex FFPP/UPE, com apoio e participação constante do Colegiado de Pedagogia, com uma menção especial à Profa. Maria do Socorro Carvalho Amariz Gomes, representado as demais pessoas envolvidas.

${ }^{24}$ Relatório Final - Roberta Gallo, Equipe BEA 2006, curso de graduação em Educador social, cultural e territorial da Ex ScForm/UNIPD, Itália, tradução do autor.
} 
com as crianças e os adolescentes acolhidos, porque nesses três meses esse foi o aspecto mais intenso e desestabilizador. Tudo girava em torno do outro, o menor em situação de vulnerabilidade. (GALLO, R., 2020, tradução do autor)

Continuando a desenrolar o novelo da linha do tempo, o ano de 2006 foi 'crucial' porque os dois caminhos relatados nesse artigo cruzaram-se quando uma delegação de professores da UNIPD participou do evento científico internacional 'Educação e Interculturalidade - Aproximando Culturas. A experiência de troca entre o Brasil e a Itália', organizado no Campus I em Salvador-BA pela UNEB. ${ }^{25}$

Em dezembro do ano de 2008 chegou ao final o segundo e último projeto de Cooperação internacional para o desenvolvimento, promovido pela EnARS e vinculado à Região do Veneto, Itália, mais já estava pronta a 'nova' e atual proposta do Progetto $B E A$, que iniciou no ano de 2009 . Um projeto social e de intercâmbio, com ciclicidade anual e três diferentes etapas (uma formação específica na Itália - pré-mobilidade-, um período de mobilidade no Brasil e a devolução da experiência na Itália - após a mobilidade), através do qual a equipe de coordenação focalizou o interesse em aprimorar cada vez mais as condições formativas para as/os estudantes universitárias/os envolvidas/os, chamadas/os a serem protagonistas em cada momento e atividade desenvolvida. Ano após ano e graças a uma constante avaliação realizada em diferentes níveis, a proposta aperfeiçoou a característica, reconhecida como peculiar, de promover e facilitar constantemente a intersecção entre o diálogo intercultural, a extensão e a aprendizagem solidária, que "proporciona aos estudantes uma formação que atende o currículo acadêmico e, ao mesmo tempo, oferece um serviço significativo que faz a diferença no bem-estar da sociedade, especialmente para comunidades e pessoas nas margens socioeconômicas.” (BRACCI, L., J. OWONA \& E. NAS, 2013). Uma interseção que, como nos sugere Giuseppe Milan no capítulo 'Viaggiamoci incontro' (vamos viajar uns ao encontro dos outros ), muitas vezes permitiu aos estudantes em mobilidade de "atravessar as fronteiras entre pensamento e ação, entre teoria e prática, colocando-as em diálogo construtivo, dando vida a uma educação que seja 'prática transformadora' coerente - como Paulo Freire espera -, a única maneira para ser um planejamento dialógico capaz de 'dar um nome ao mundo'" (MILAN, G., 2000, pp.112,113). Uma reflexão constante sobre as atividades realizadas, como base de um processo formativo, realizada através de grupos focais segundo o ciclo da aprendizagem solidária, permitiu nos protagonistas, o reconhecimento desse processo interior de conscientização, elaboração e, as vezes, superação de algumas situações limites, vinculantes:

Comunicar, esse é exatamente o ponto, usando habilidades, recursos, capacidades que você nem sabia de ter. É conhecer a si mesmo antes de conhecer o outro. É saber esperar o tempo do outro que deve decidir se ele quer entrar em um relacionamento com você. É saber ouvir sem

\footnotetext{
${ }^{25}$ Entre os demais, participou a Profa. Cristina Amplatz, referente pela Ex ScForm UNIPD do Acordo de colaboração com a Ex FFPP/UPE e orientadora do Trabalho de Conclusão de Curso de Nicola A. que foi convidado a apresentar, ao longo do evento, os resultados do primeiro projeto BEA e do próprio TCC, cujo título foi: 'BEA 2002' e o Tessor de Redes. Um projeto e um modelo na área da cooperação de-centralizada para o desenvolvimento. Discutido em data 03 de Março de 2003, na Ex ScForm/UNIPD, na Itália.
} 
pretender já ter uma resposta pronta, uma determinada solução. É se envolver, se expor, compartilhar sentimentos e emoções. ${ }^{26}$

Com um grande trabalho em rede de todas as instituições italianas e brasileiras envolvidas no novo projeto, nos dias 16 e 17 de novembro de 2011, no SEST SENAT em Petrolina, realizaram-se a $1^{\text {a }}$ Conferência Internacional de Educação Brasil-Itália cujo título foi: Interculturalidade, Formação e Docência na Educação Contemporânea e $1^{\circ}$ FÓRUM do Progetto BEA cujo título foi: O Laço Entidade-Família através do protagonismo Juvenil. ${ }^{27}$ Tais iniciativas fizeram parte da evento promovido pelo Consulado da Itália em Recife 'Momento Itália / Brasil 2010 - 2011'.

No ano de 2012 a EnARS e a Pró Reitoria de Extensão PROEX ${ }^{28}$ da Universidade Federal do Vale do São Francisco/UNIVASF assinaram um termo de cooperação técnica abrindo novos horizontes ao desenvolvimento do Progetto BEA em Petrolina. Tais horizontes previam a participação das/os intercambistas italianas/os em projetos de extensão da PROEX, tais quais, por exemplo 'Contextos de acolhimento - Promovendo práticas de atenção psicossocial a crianças e adolescentes em situação de abrigo' (anos de 2012 e 2013). Outras atividades, consideradas pelas pessoas envolvidas de grande relevância nesse novo cenário, foram as experiências interculturais e de educação entre pares (em inglês peer education) tais quais os cursos de língua e cultura italianas, promovidos pela PROEX e ministrados pelo coordenador do projeto junto aos estudantes italianos em mobilidade, abertos a discentes, técnicos e docentes da UNIVASF e à comunidade. Nos últimos anos de colaboração destacam-se as parcerias realizadas entre o projeto internacional e: o projeto de extensão da UPE, Campus de Petrolina 'A aprendizagem solidária como instrumento de participação e inserção social de jovens em situação de vulnerabilidade social no município de Petrolina-PE ${ }^{29}$; a Residência Multiprofissional de Saúde Mental-RMSM da Univasf, um Centro de Atenção Psicossocial-CAPS Infanto-juvenil na cidade de Juazeiro-BA (que constitui um dos cenários de aprendizagem da RMSM), o Núcleo de Mobilização Antimanicomial do Sertão/Numans ${ }^{30}$ e o grupo de pesquisas do Observatório de Políticas e Cuidado em Saúde/Univasf.

Em 2015, o interesse em desenvolver um doutorado em cotutela internacional na área da educação, levou o Nicola A. ao encontro com a Direção do Departamento de Ciências Humanas (DCH), campus III da Universidade do Estado da Bahia, na cidade vizinha de Juazeiro-BA, Brasil. Para a Profa. Márcia Guena dos Santos, naquela época Diretora do DCH III, a proposta foi "uma importante oportunidade de realizar um intercâmbio cultural e acadêmico", porque:

\footnotetext{
${ }^{26}$ Relatório Final - Isidora Zanon, Equipe BEA 2015, Curso de Graduação em Ciências da Educação e da formação -SED, FISPPA, UNIPD Padova.

${ }^{27}$ Realização: Associação EnARS, Universidade de Pernambuco/UPE, APAE Petrolina, CEMAM Ação Social, FUNASE, PETRAPE, UNIVASF; Apoio: Prefeitura Municipal de Petrolina, SEST SENAT, Consulado da Itália em Recife; Patrocinadores: Colégio OBJETIVO Petrolina, SEDEST Petrolina, Associazione Madre Teresa, Villa del Conte, Padova, Itália.

${ }^{28}$ Na pessoa da Ex Pró-Reitora de Extensão Profa. Lúcia Marisy Souza Ribeiro de Oliveira.

${ }^{29}$ Coordenado pela Profa. Virgínia Pereira da Silva Ávila, da UPE, Campus de Petrolina-PE.

${ }^{30}$ Movimento social em prol da Reforma Psiquiátrica, coordenado pela Profa. Barbara Eleonora Bezerra Cabral da UNIVASF.
} 
Um doutorado em co-tutela significa muito para todas as universidades envolvidas. Percebe-se que em um intercâmbio há a valoração do que a gente desenvolve e, também, as perspectivas do outro, de como ele tem pensado as questões e isso é uma troca fundamental, porque a acaba-se descobrindo aspectos da realidade que a não eram consideradas. (SANTOS, M.G., 2020)

No sentido de um diálogo e de uma troca enriquecedora, por exemplo, "Saber que a Universidade de Padova tem uma dedicação aos estudos de Paulo Freire foi uma descoberta muito importante." (IBIDEM, 2020)

A existência de um acordo bilateral entre a UNIPD e a UNEB e a assinatura de um acordo conjunto de supervisão de doutorado entre o Curso de Ciências Pedagógicas e Educacionais do Departamento de Filosofia, Sociologia, Pedagogia e Psicologia Aplicada/FISPPA, UNIPD, e o Programa de Pós-graduação/PPGEduC em Educação e Contemporaneidade, $\mathrm{UNEB}^{31}$, criaram as condições para a implementação de uma pesquisa capaz de sistematizar as atividades realizadas até aquele ano e ir além. $\mathrm{O}$ ano 2016 foi determinante principalmente por duas razões. A primeira foi a escolha das temáticas principais e do título da pesquisa. A internacionalização acadêmica e o diálogo intercultural, a responsabilidade social da universidade com a própria comunidade (extensão) e a aprendizagem solidária foram os pontos cardeais de um novo mapa e a pedagogia intercultural foi a Bússola para uma viagem de exploração das intersecções entre tais pontos através da pesquisa nomeada INTEREURISLAND ${ }^{32}$. A segunda razão foi a convergência com a 'rota' traçada pela proposta das Cátedras Scholas da Fundação Pontifícia SCHOLAS OCCURRENTES, promovida por Papa Francisco ${ }^{33}$.

A viagem tornou-se tanto simbólica quanto real, levando as e os protagonistas a apresentarem a pesquisa em seminários e congressos no Brasil, na Itália, na Argentina, na Espanha, no Israel e na Irlanda. Segundo o Prof. Giuseppe Milan, supervisor da pesquisa pelo Departamento FISPPA/UNIPD, a experiência de doutorado em cotutela foi valiosa e inovadora por diversos motivos: em primeiro lugar, pelo fato de ter como 'foco de pesquisa' os intercâmbios entre universidades (em particular entre Brasil e Itália e especificamente, entre a UNEB e a UNIPD), um tópico de pesquisa significativo para demonstrar a importância educacional da internacionalização e promovê-la em geral; em seguida, pelo fato de ter incentivada a formação de estudantes no 'horizonte intercultural'; além disso, pela importância, agora essencial, tanto da metodologia da aprendizagem solidária, quanto da responsabilidade social da universidade como temáticas abordadas dos pontos de vista teórico e prático.

\footnotetext{
312016 - 2018 Doutorado em cotutela com a Supervisão dos Prof. Giuseppe Milan e Prof. Luca Agostinetto (FISPPA UNIPD) e do Prof. Augusto Cesar Rios Leiro (PPGEduC UNEB).

${ }^{32}$ INTERsectoral, 'Extensão Universitária', Research, Interculture and Service Learning; Approaching to a New Development. Material disponível no link: http://intereurisland.blogspot.com

${ }^{33}$ Espaços de formação, reflexão e ação conectados em uma grande rede, na qual cada sujeito (professores, pesquisadores, estudantes) é enriquecido no encontro com o outro, através dos vínculos que se desenvolvem entre as diferentes universidades, escolas e Projetos sociais. Material disponível no site: https://www.scholasoccurrentes.org/it/campaigns/scholas-catedras/
} 
O doutorando assumiu essa tarefa de pesquisa-ação-formação com grande comprometimento e inteligência, provando ser um 'agente articulador' fundamental, um "trait d'union", entre as universidades, em uma perspectiva de reticularidade sistêmica - ainda em execução - que introduz uma 'relação de qualidade' no contexto da comunicação global - agora também favorecida pelas novas tecnologias - que, para não ser estéril e amorfa - realmente precisa de uma autêntica 'consciência' (diria o Paulo Freire), ou seja 'geradora de sentido', capaz de promover a ética, os valores, o diálogo, a dimensão responsável, segundo a abordagem inovadora da 'ecologia integral'. (MILAN, G., 2020, tradução do autor)

Para o Prof. Augusto Cesar Rios Leiro, coorientador da pesquisa pelo programa de Pós-graduação em Educação e Contemporaneidade-PPGEduC da UNEB e, na época, coordenador do mesmo programa, "A Universidade se realiza pelo ensino, pela pesquisa e pela extensão, mas quando um trabalho se propõe a reunir estas três dimensões para pensar a formação de sujeitos juvenis é sempre um desafio ordinário e extraordinário.” (RIOS LEIRO, A.C., 2016)

Ao redigir e discutir a tese de doutorado em março do ano de 2018, foram mais os novos horizontes abertos do que as respostas as questões da pesquisa. Uma consequência quase direta, após a finalização desse ciclo, foi a participação ao edital do Programa Nacional de Pós Doutorado-PNPD vinculado ao PPGESA. A partir do mês de junho de 2018 começou um novo projeto de pesquisa, atualmente em desenvolvimento, com a supervisão do Prof. Edmerson dos Santos Reis. A viagem continua nas interseções das grades áreas consideradas, mais com o interesse em compreender qual é a relevância da Educação Contextualizada no diálogo intercultural e no processo de formação das jovens gerações para uma cidadania ativa no próprio contexto e no mundo e vice-versa.

Em dezembro de 2018, com a aprovação e o cofinanciamento da proposta apresentada ao Edital n²9/2018: Chamada pública de propostas de eventos científicos no âmbito do Programa de Apoio a Eventos no País - PAEP/CAPES, começou-se a organização de um evento científico internacional cujo título foi I Colóquio Brasil Itália.

\section{O Evento Científico}

O evento científico internacional I Colóquio Brasil Itália - A educação contextualizada e o diálogo intercultural na implementação de novas estratégias de internacionalização da extensão no PPGESA DCH III/UNEB, realizou-se nos dias 31 de Júlio (pré-colóquio) e de 21 a 23 de Agosto de 2019, no Departamento de Ciências Humanas DCH III da Universidade do Estado da Bahia (UNEB), de Juazeiro-BA.

Um evento promovido pelo Programa de Pós-graduação em Educação, Cultura e Territórios Semiáridos / PPGESA, do Departamento de Ciências Humanas / DCH III UNEB, através de uma proposta, vinculada ao projeto de pesquisa e intercâmbio INTEREURISLAND, submetida ao Edital CAPES/PAEP 29/2018, aprovada e cofinanciada pela CAPES. O evento foi realizado com o apoio da Universidade Federal do Vale do São Francisco UNIVASF, do Departamento de Filosofia, Sociologia, 
Pedagogia e Psicologia Aplicada FISPPA da Universidade de Padova/UNIPD, da associação EnARS de Padova, Itália e da Fundação Pontifícia SCHOLAS OCCURRENTES.

A seguir são apresentadas algumas das características principais do evento:

\section{As finalidades}

O evento teve como objetivo geral o desenvolvimento e fortalecimento de uma discussão e de uma reflexão sobre novas estratégias de intercâmbio e internacionalização da extensão, através de uma abordagem ao conceito GloCal (do contexto para o mundo), para docentes, pesquisadores e discentes de graduação e pós-graduação, das Instituições de Ensino Superior do contexto social das cidades de Juazeiro-BA e Petrolina-PE, Brasil e das cidades de Padova e Rovigo, Itália.

As finalidades foram:

O desenvolvimento de ações de internacionalização e de extensão acadêmicas contribuindo com o desenvolvimento do grupo de internacionalização do DCH campus III, UNEB, Juazeiro-BA;

O fortalecimento dos vínculos entro o DCH Campus III, UNEB, Juazeiro-BA e o Departamento FISPPA da Universidade de Padova, Itália para atividades de intercâmbio tanto a nível de graduação como de Pós-Graduação;

A apresentação dos resultados da implementação das práticas e dos processos do ciclo INTEREURISLAND com foco na educação contextualizada, nos cursos de graduação e no curso de Mestrado Multidisciplinar em Educação, Cultura e Territórios Semiáridos PPGESA do DCH, Campus III, UNEB, Juazeiro-BA em colaboração com o Departamento de Filosofia, Sociologia, Pedagogia e Psicologia Aplicada da Universidade de Padova, Itália;

O fortalecimento de uma discussão e reflexão sobre a relevância da educação contextualizada no desenvolvimento da educação GloCal e vice-versa e novas estratégias de internacionalização da extensão e da aprendizagem solidária, tanto no PPGESA, como no DCH III, com estudantes, pesquisadores e professores envolvidos nas atividades de intercâmbio e extensão;

A contribuição com as atividades acadêmicas do DCH III e do PPGESA/UNEB;

A realização de uma publicação em conjuntos entre o PPGESA, o DCH III/UNEB e o FISPPA/UNIPD;

O evento previu uma Comissão organizadora, um Comitê científico, uma Coordenação geral e um Grupo de Monitores; foi público e aberto a docentes, pesquisadores e discentes de graduação e pós-graduação das Instituições de Ensino Superior dos contextos sociais das cidades de Juazeiro-BA e Petrolina-PE, Brasil e das cidades de Padova e Rovigo, Itália e a profissionais da educação básica e de áreas afins.

\section{A programação}

Dia 21/08/2019

Local: Auditório ACM - Campus III

$8 \mathrm{~h} 00$ - Credenciamento e Boas Vindas

9h00 - Apresentação Cultural 
9h20 - Abertura Oficial do Evento

10h00 - Conferência de abertura: "Pedagogia e diálogo intercultural”, Prof. Giuseppe

Milan (UNIPD, Itália)

$12 \mathrm{~h} 15$ - Intervalo

15 h00 - Mesa "Educação Contextualizada e Educação GloCal: pertencimento na mundialização ou Formação para uma Cidadania planetária", Prof. Edmerson Reis (PPGESA/UNEB), Prof. Isnaldo Coelho (UNIVASF), Prof. Natanael Reis Bomfim (SERINT/UNEB) e Prof. Augusto Cesar Rios Leiro (PPGEDUC/UNEB). Coordenação: Profa. Carla Paiva (PPGESA/UNEB)

17 h00 - Do Local ao Global, novas estratégias de internacionalização da extensão: $\mathrm{PhD}$ Nicola Andrian (PNPD -PPGESA/UNEB). Coordenação: Prof. Edmerson Reis (PPGESA/UNEB)

17h30 - Laboratório INTEREURISLAND: Experiência na sala de aula de Relações Interpessoais e dinâmicas de grupo. Coordenação: PhD Nicola Andrian (PNPD PPGESA/UNEB)

Dia 22/08/2019

Local: Auditório ACM - Campus III8h30 - Atividade de extensão - visitas $12 \mathrm{~h} 30$ Intervalo 14h30 - Socialização das atividades de extensão - visitas e reflexão segundo o Ciclo da Aprendizagem Solidária. Coordenação: PhD Nicola Andrian (PNPD -PPGESA/UNEB) 15h30 - A Aprendizagem Solidária: PhD Katia Gonçalves Mori (Coordenação da Rede Brasileira da Aprendizagem Solidária) e PhD Carina Rossa (SCHOLAS OCCURRENTES)

17h30 - Projeto de Extensão UNIPD Mentor Up: Prof. Massimo Santinello (UNIPD) 17h45 - A Música como a intercultura - é uma experiência subversiva: PhD Simonetta Bungaro (Conservatório Trento, Itália)

18h15 - Lançamento de livros e Apresentação cultural

Dia 23/08/2019

Local: Auditório ACM - Campus III

9h00 - Mesa "Curricularizando a extensão": Profa. Adriana Marmori (PROEX/UNEB), Profa. Lucia Marisy (PROEX/UNIVASF), Prof. Odair França de Carvalho (PROEC/UPE). Coordenação: Profa. Edonilce Barros (PPGESA/UNEB) 10h30 - Mesa "Extensão e diálogo intercultural - Interseções": Profa. Edilane Carvalho Teles (UNEB), Prof. Nilton Araújo (UNIVASF), Profa. Barbara Eleonora Cabral (UNIVASF) e Prof. Giuseppe Milan (UNIPD). Coordenação: Profa. Márcia Guena (UNEB)

$12 \mathrm{~h} 30$ - Intervalo

14h30 - Mobilidade internacional, extensão e aprendizagem solidária - o olhar das/os discentes e das Instituições envolvidas - Relatos de Experiência Brasil e Itália: Jamile Soares da Silva (UNEB), Maria Spalletta e Maurizio Dorsa (UNIPD), Fernanda Maria Lins e Silva (Pastoral da Mulher), Elzirene Oliveira (Case Gey Espinheira), Isabella Polloni (Ass. EnARS), Beatrice Girotto (Coop. Peter Pan), Roberta Lorenzetto (Coop. Porto Alegre). Coordenação: Profa. Tânia Hetkowski (PPG/UNEB). 
17h00: Cerimônia de Encerramento: Plantio da Árvore do Programa SCHOLAS OCCURRENTES e Assinatura da Carta "Pela construção de uma cidadania planetária" 18 h00 Noite cultural "Bella Ciao": Grupo Percussivo Baque Opará e Banda Musaikón.

Segundo o prof. Edmerson dos Santos Reis, o I Colóquio foi uma iniciativa que abriu e continua abrindo possibilidades concretas de aproximação entre a graduação e a pós-graduação do DCH - III/UNEB, com a UNIPD e muitas outras oportunidades que vão se desdobrando com outras universidades do mundo inteiro. "A internacionalização, fundada na perspectiva da interculturalidade é sempre um colocar-se na horizontalidade das relações de respeito e sintonia naquilo que cada país, universidade e professores realizam, a partir de onde se encontram, reafirmando sempre a necessidade de uma educação contextualizada e o diálogo permanente entre os saberes locais e globais." (REIS, E.S., 2020)

Para a Profa. Carla Paiva, na época do evento coordenadora do PPGESA, o I Colóquio foi uma oportunidade para "[...] estreitar os laços de pesquisa, produção e extensão entre Brasil e Itália, principalmente através dos nossos cursos de graduação, na área de educação e comunicação, mais também através do programa de Pós Graduação PPGESA.'(TV UNEB Juazeiro, 2019)

\section{Conclusões}

Ao começar a recolher notícias e informações sobre as linhas do tempo dos caminhos percorridos até o evento, o autor deste artigo mergulhou, de fato, em um mar de relações e vínculos entre pessoas e instituições brasileiras e italianas, através das quais foram realizadas muitas atividades que, pelas épocas nas quais concretizaram-se, podem ser consideradas como inovadoras e precursoras sob diversos pontos de vista. Foram simples ações, projetos mais elaborados e até grandes processos que abriram trilhas e horizontes a respeito das temáticas tais quais o diálogo intercultural, a internacionalização acadêmica, a extensão e a aprendizagem solidária.

Ao organizar tanta riqueza e tentar descrevê-la, uma primeira reflexão, que nasceu espontânea, fez-se a respeito da centralidade da 'Relação' entre as pessoas em todos os níveis e grãos. Relações através das quais, e somente através das quais, os caminhos foram percorridos com curiosidade, entusiasmo, desafio, abertura, dedicação e ... rigor científico, alcançando metas que, talvez, nem tinham sido imaginadas ao fazer os primeiros passos. Uma reflexão que levou a perceber as relações entre as pessoas como base, fundamento, significação das relações entre culturas, pelo fato que tais caminhos foram percorridos por pessoas que veicularam e transmitiram os próprios conhecimentos, hábitos e costumes, crenças e valores recebendo em troca riquezas do mesmo tamanho no encontro com outros seres humanos e determinando, juntos, novos sentidos.

Uma segunda reflexão surgiu como natural consequência à primeira em relação ao 'Diálogo Intercultural' que, pelas experiências realmente vivenciadas, toma forma e se revela como 'autêntico' na medida em que os sujeitos que se relacionam são capazes de se colocarem em um plano de absoluta paridade e se conscientizar a respeito de 
possíveis limites tais quais polarizações e hierarquizações desumanizadoras, preconceitos e formas de racismo, que precisam ser desconstruídos, perpassados e superados.

Uma terceira reflexão se fez a respeito do papel fundamental que a universidade pode e precisa ter no que diz a respeito da formação de cidadãos que sejam capazes de valorizar cada vez mais o próprio contexto e abrir mente e alma ao mundo. A universidade como uma instituição que baseia, planeja e exerce o ensino, a pesquisa e a extensão entrelaçando vínculos e diálogos em um plano de horizontalidade, tanto a nível local, com a própria comunidade, quanto a nível internacional com outras instituições de ensino superior e entidades de outras comunidades. Uma universidade que, neste diálogo contínuo saiba tanto ensinar, como compartilhar conhecimentos, quanto aprender.

Mantendo firme na mão a Bússola da pedagogia intercultural e seguindo as trilhas das reflexões acima citadas, o artigo trouxe um olhar histórico a respeito de dois caminhos que ao se encontrar determinaram as condições para a realização de um evento científico, até aquele momento único na sua espécie para o contexto específico do PPGESA, no DCH III da UNEB em Juazeiro da Bahia. Um evento através do qual quis-se fomentar uma discussão e uma reflexão a respeito da relevância da educação contextualizada no desenvolvimento de novas estratégias de internacionalização da extensão e da aprendizagem solidária e fortalecer os vínculos locais, entre o PPGESA e o DCH III da UNEB e outras Instituições de Ensino Superior e entidades e projetos da comunidade, e internacional com o Departamento FISPPA da UNIPD e a rede Mundial do programa Cátedras Scholas da Fundação SCHOLAS OCCURRENTES, promovida pelo Papa Francisco.

O evento encerrou-se com três atos tanto concretos como simbólicos.

Um, foi a assinatura de uma Carta de intenções que diz a respeito dos compromissos dos participantes para o futuro, “[...] como resultado de promoção de ações efetivas que aprimorem as discussões iniciadas neste evento e a sua continuidade como inspiração para a institucionalização da internacionalização da extensão, da pesquisa e das práticas inovadoras de ensino e iniciativas da Educação Contextualizada formal e não formal, fundadas na perspectiva da internacionalização, da descolonização, da aprendizagem solidária $\mathrm{e}$ da interculturalidade nas relações multilaterais entre universidades do Brasil (UNEB, UNIVASF, UPE) e Itália (Universidade de Pádua) e outras que venham a se unir no propósito da continuidade das ações e reflexões."

Um outro ato foi o plantio de um pé de Umbuzeiro no terreno do DCH III, que diz a respeito do valor de algo que cresce e se desenvolve afundando suas raízes, para o próprio nutrimento, no semiárido da Região Nordeste do Brasil, a nossa 'Mãe' Terra que abriga e sustenta as pessoas que aqui nasceram e moram e os estrangeiros, os viajantes que por aqui passam.

O último foi o de pintar um Mapa do Mundo invertido, com as digitais de cada participantes coloridas com cores diferentes, que diz respeito à riqueza e beleza de um mundo formado por pessoas únicas, diferentes, mas unidas pelos valores e aspirações. Um Mapa do Mundo ainda inacabado, que, chegando do Congresso Internacional SCHOLAS 2019, de Nova York, passou para o I Colóquio Brasil Itália, em Juazeiro-BA e, agora, continua uma viagem rumo ao encontro de outras pessoas em contextos diferentes, até chagar na cidade de Roma, na Itália para poder receber, como última gota 
de cor, a digital de Papa Francisco para representar o mapa de uma nova viagem chamada 'A Universidad del Sentido'.

\section{Referências}

ALVES DE ALMEIDA, Ivanildo. Entrevista concedida a Nicola Andrian, 09 Jul. 2020.

AMATURO Enrica. Metodologia della ricerca sociale. Bologna: UTET Università, 2012.

ANDRIAN, Nicola. INTERERISLAND: Una ricerca e un modello in merito a processi di Internazionalizzazione di esperienze di Responsabilità Sociale dell'Università. PLURAIS, Salvador-BA, v. 2, n. 2, p. 46-67, abr./ago. 2017.

; POLLONI, I. Progetto BEA - Educazione, formazione e intercultura - Un Ponte fra l'Italia e il Brasile, Disponível em: http://www.enars.it/joomla/it/com-joomgalleryimage-manager/progetti/progetto-bea . Acesso em: 03 Mar. 2020.

BAHIA. Universidade do Estado da Bahia / ITALIA. Università degli Studi di Padova. Accordo di collaborazione tra la Facoltà di Scienze della Formazione dell'Università di Padova (Italia) e la Facoltà di Educazione FAEEBA dell'Università dello Stato di Bahia (Brasile). Valido per gli anni $(1997,1998,1999)$ (Mimeo).

BOSCOLO, Gianni. Entrevista concedida a Nicola Andrian, 19 Maio 2020.

BRACCI, L., J. OWONA \& E. NAS Community Engagement through International ServiceLearning: How a Foreign Student can Become a Social Actor in the Host Society, International Center for Intercultural Exchange, Siena Italian Studies, Italy, 2013.

CAPES. A internacionalização na Universidade Brasileira: resultados do questionário aplicado pela CAPES. Brasília: Edição e composição: Diretoria de Relações Internacionais, 2017.

CEDE - Istituto Nazionale per la valutazione del sistema dell'istruzione. Guida metodologica agli Studi di Caso. Frascati Roma: Progetto QUASI, 2001.

CORBETTA, Piergiorgio. Metodologia e tecniche della ricerca sociale, $2^{\mathrm{a}}$ Ed., Bologna: Il Mulino, 2014.

EnARS, Associação, Progetto BEA - Educazione, formazione e intercultura - Un Ponte fra l'Italia e il Brasile, Disponível em: http://www.enars.it/joomla/it/com-joomgallery-imagemanager/progetti/progetto-bea . Acesso em: 03 Mar. 2020.

FREIRE, Paulo. Pedagogia da tolerância. Ana Maria Araújo Freire (Org.). São Paulo: UNESP, 2005.

Conscientização e Alfabetização: uma nova visão do processo. Recife: Revista de Cultura da Universidade do Recife. № 4; Abril-Junho, 1963.

FREIRE, Paulo \& FAUNDEZ, Antônio. Por uma Pedagogia da Pergunta. $3^{\text {a }}$ Ed. Rio de Janeiro: Paz e Terra, 1985.

FÓRUM DE PRÓ - REITORES DE EXTENSÃO DAS UNIVERSIDADES PÚBLICAS BRASILEIRAS. Política Nacional De Extensão Universitária: Recife, Editora Universitária, UFPE, 2013. 
GALERI, Patrizia (A cura di). Ambientando. Riflessione pedagogica ed esperienze didattiche per l'ambiente. Milano: EDUCatt., 2009.

GALLO, Roberta. Entrevista concedida a Nicola Andrian, 22 junho 2020.

GEORGESCU, Mara. T-KIT 4 - Intercultural Learning 2ªEdição. Strasbourg: COUNCIL OF EUROPE, 2018.

KÜSTER, Angela; MATTOS, Beatriz. Educação no contexto do semiárido brasileiro. Fortaleza: Fundação Konrad Adenauer, 2004.

MARTINS, Josemar da Silva. Anotações em torno do conceito de educação para a convivência com o Semi-árido. In: Secretaria Executiva da RESAB. Educação para a convivência com o Semiárido: Reflexões teórico-práticas. 2ª Ed., Juazeiro-BA: Selo editorial RESAB, 2006.

MILAN, Giuseppe. A tu per tu con il mondo. Educarci al viaggiare interculturale nel tempo dei muri. Lecce: Pensa MultiMedia, 2020.

MILAN, Giuseppe. Entrevista concedida a Nicola Andrian, 21 Jul. 2020.

PEREIRA, Vanderléa Andrade. Multiplos olhares sobre a educação no Semiárido Brasileiro. Juazeiro-BA: Gráfica e Editora Printpex, Caderno Multidisciplinar Educação e Contexto do Semiárido Brasileiro, Ano $10 \mathrm{n}^{\circ} 08$, dezembro, 2016.

PEROZA, Juliano. Reflexões sobre cultura e diversidade cultural em Paulo Freire: Um humanismo crítico para a transculturalidade em educação. Agência: CAPES, 2012.

REIS, Edmerson dos Santos. Educação para a convivência com o semiárido: desafios e possibilidades. in SOUSA e SILVA, Conceição de Maria de; LIMA, Elmo de Souza; CANTALICE, Maria Luiza de; ALENCAR, Maria Teresa de Alencar; SILVA, Walderene Alves Lopes da. Semiárido Piauiense. Educação e contexto. Campina Grande-PB: INSA, 2010. Entrevista concedida a Nicola Andrian, 21 Julio 2020.

RIOS LEIRO, Augusto Cesar. Entrevista concedida a Nicola Andrian, 21 dezembro 2016.

ROLAND, R. Globalization: Social Theory and Global Culture. London: SAGE Publications, 1992.

SANTOS, Márcia Guena. Entrevista concedida a Nicola Andrian, 18 Julio 2020.

SEIBERT SANTOS, Cínthia Maria. Entrevista concedida a Nicola Andrian, 23 maio 2020.

SMITT, Craig N.. The Case Study: a useful research method for information management. In: Journal of Information Technologies n.5, pp. 123 - 133, Palgrave Macmillan UK, 1990.

STAKE, R. E.. The art of case study research. Thousand Oaks, CA: Sage Publications, 1995.

TELES, Edilane Carvalho. Entrevista concedida a Nicola Andrian, 9 maio 2020.

TRINCHE.RO, Roberto. I metodi della ricerca educative. Bari: Edizioni Laterza, 2004

TURUS, G. Ad occhi aperti. Padova: Esedra editrice, 2002.

TV UNEB Juazeiro, $\mathbf{1}^{\mathbf{0}}$ Colóquio Brasil-Itália, Webtv.Uneb Núcleo de Juazeiro, 2019, disponível no link: https://www.youtube.com/watch?v=sbciTZoFZg4 
UNESCO. Guidelines on Intercultural Education. Parigi, Section of Education for Peace and Human Rights, Division for the Promotion of Quality Education, Education Sector, 2006.

UNESCO. Educazione alla cittadinanza globale - Temi e obiettivi di apprendimento. Roma: Centro per la Cooperazione Internazionale, 2018.

YIN, Robert K.. Estudo de caso. Planejamento e Métodos. 2ªdição, São Paulo: BOOKMAN, 1994.

ZAINAL, Z.. Case study as a research method, Journal of JurnalKemanusiaan, Vol.9, No. January, PP.1-6, 2007.

ZAMPERLIN, Patrizia. Entrevista concedida a Nicola Andrian, 01 junho 2020. 